\title{
Different effects of corticotropin-releasing factor and urocortin 2 on apoptosis of prostate cancer cells in vitro
}

\author{
Lai Jin*, Qichun Zhang*, Rui Guo*, Lina Wang, Juejin Wang, Rong Wan, \\ Rongjian Zhang, Youhua Xu and Shengnan Li
}

Jiangsu Provincial Key Lab of Cardiovascular Diseases and Molecular Intervention, Department of Pharmacology, Nanjing Medical University, Nanjing 210029, People's Republic of China

(Correspondence should be addressed to S Li; Email: snli@njmu.edu.cn)

*(L Jin, Q Zhang and R Guo contributed equally to this work)

\begin{abstract}
Urocortin (Ucn), a corticotropin-releasing factor (CRF)-related neuropeptide binding both CRF type 1 receptor (CRFR1) and CRFR2, has recently been found in prostate cancer. However, no report has yet been known to elucidate the roles of Ucn in prostate cancer via the two receptors. In this study, the expression of both CRFR1 and CRFR2 in the mouse prostate cancer cell line RM-1 were detected and cellular apoptosis was monitored in the presence of CRF or Ucn2, the CRFR1- and CRFR2-selective agonist respectively. CRF promoted apoptosis while Ucn2 exerted the opposite effect. $\mathrm{CRF}$ reduced $\mathrm{Bcl}-2$ expression, induced Bax expression, and hyperpolarized the mitochondrial membrane potential to activate caspase-9. On the contrary, Ucn2 increased Bcl-2 expression and decreased Bax expression, in which phosphorylation of Akt and cyclic AMP response element-binding (CREB) was involved. Pretreatment with phosphatidylinositide 3-kinase/Akt inhibitor (LY-294002) prior to Ucn2 led to downregulation of CREB phosphorylation and hence reduced $\mathrm{Bcl}-2$ expression. These effects of CRF and Ucn2 were abolished by antalarmin (Anta) and antisauvagine-30, the CRFR1- and CRFR2-selective antagonist respectively. In LNCaP cell line, similar effects on cell apoptosis by CRF and Ucn2 were observed. In summary, our results demonstrated CRFR1 and CRFR2 expression in prostate cancer and indicated the opposite apoptotic roles of the two different CRFRs. These data may contribute to uncovering the pathophysiological function of endogenous Ucn in prostate tumorigenesis and progression.
\end{abstract}

Journal of Molecular Endocrinology (2011) 47, 219-227

\section{Introduction}

Corticotropin-releasing factor (CRF) and Urocortin (Ucn) have been found to be over-expressed in human reproductive tumors such as ovarian cancer (Suda et al. 1986), endometrial adenocarcinoma (Miceli et al. 2009), and hydatidiform mole (Okamoto et al. 1990). However, the special effects of CRF family peptides on cellular apoptosis in reproductive tumors are controversial at present. Evidence indicated that CRF could inhibit human endometrial adenocarcinoma cell growth (Graziani et al. 2002), while others suggested that CRF repressed apoptosis (Minas et al. 2007). We previously reported that $U c n$ could inhibit tumor growth and angiogenesis in human cancers via CRF type 2 receptor (CRFR2; Wang et al. 2008). To date, few investigations have been reported on CRF family and prostatic tumor. Ucn, which was first detected in prostatic adenocarcinoma by RT-PCR and immunohistochemistry (Arcuri et al. 2002), is speculated to be related to prostate tumorigenesis, progression, and neoangiogenesis via CRFR2 (Tezval et al. 2009).
However, detailed mechanisms of CRF peptides in the progress of prostate cancer are far from clear.

As is well known, the CRF family contains CRF, Ucn, Ucn2, and Ucn3 (Lewis et al. 2001). CRF has a higher affinity for CRFR1, Ucn binds with both receptors (Vaughan et al. 1995), and the other two peptides are regarded as the natural ligands for CRFR2 (Reyes et al. 2001). It is reported that the affinity of CRF to CRFR1 is about 20-fold (17/0.95) of that to CRFR2, and Ucn binds with both receptors equally $(0 \cdot 16 / 0 \cdot 41$; Vaughan et al. 1995). To investigate concrete roles of these two receptors, we used CRF (R1 agonist) and Ucn2 (R2 agonist) substituting for Ucn in vitro.

In developed countries, prostate cancer is the second most frequently diagnosed cancer and the third most common cause of death due to cancer in men (Jan-Erik \& Gunnar 2008). Although advanced prostate cancer is initially responsive to hormonal therapy, cancers inevitably progress in an androgen-independent fashion with virtually all tumors evolving into more aggressive androgen refractory disease (Cai et al. 2008). The major molecular defects in androgen-independent 
prostate cancer may lead to the inability of initiating apoptosis in response to androgen ablation (Chaudhary et al. 1999). One family of genes regulating apoptosis is the $\mathrm{Bcl}-2$ gene family, which constitutes positive and negative regulators (Schendel et al. 1998). Among them, Bcl-2 (death suppressor) and Bax (death promoter) play an important role in forming pores in mitochondria, which leads to intrinsic apoptosis in prostate tumor cells. The positive correlation between the ratio of $\mathrm{Bcl}-2 / \mathrm{Bax}$ and poor therapeutic outcome has been reported (Rajendran \& Kao 2007). Thus, seeking a way to lower the Bcl-2/Bax ratio, which means repressing expression of $\mathrm{Bcl}-2$ and promoting $\mathrm{Bax}$ expression, has been significantly implicated in prostate cancer therapy.

As mentioned above, the Bcl-2 family plays an important role in the progress of prostatic tumor and lowering the ratio of $\mathrm{Bcl}-2 / \mathrm{Bax}$ contributes to tumor inhibition. Tsatsanis et al. (2005) suggested that Ucn and Ucn2 induced macrophage apoptosis via CRFR2, in which the pro-apoptosis pathway activated by the proapoptotic Bax and Bad proteins was involved. Cyclic AMP response element-binding (CREB) protein, an activated transcription factor of $\mathrm{Bcl}-2$, is reported to be phosphorylated by CRF family peptides (Yamamori et al. 2004). These results highly suggest that CRF family might influence prostatic tumor growth by affecting Bcl-2/Bax ratio. In order to get more insight into the relevant mechanisms of $\mathrm{CRF}$ and $\mathrm{Ucn} 2$ on apoptosis, RM-1 cells were used and the effects of CRF family peptides on the $\mathrm{Bcl}-2$ / Bax ratio were investigated in this study. To corroborate the effects of CRF/Ucn2, another prostate cancer cell line, LNCaP, was tested by MTT assay for viability and flow cytometry for apoptosis.

\section{Materials and Methods}

\section{Cells and reagents}

Mouse prostate cell line RM-1 (Baley et al. 1995) and human prostate cell line LNCaP were obtained from the Institute of Biochemistry and Cell Biology (Shanghai, People's Republic of China). The cells were cultured in RPMI-1640 with $10 \%$ fetal bovine serum, $1 \%$ penicillin-streptomycin, and incubated at $37^{\circ} \mathrm{C}$ in a humidified atmosphere of $95 \%$ air and $5 \% \mathrm{CO}_{2}$.

CRF, Ucn2 (mouse), CRFR1 antagonist antalarmin (Anta), CRFR2 antagonist antisauvagine-30 (Anti-30), rhodamine-123, 4,6-diamidino-2-phenylindole (DAPI), and $\mathrm{Cy}$-3-conjugated goat anti-rabbit IgG were obtained from Sigma. CRFR1 and CRFR2 antibodies were purchased from Santa Cruz Biotechnology (Santa Cruz, CA, USA). Bcl-2 and Bax antibodies were purchased from Abcam (Cambridge, UK). Specific antibodies to Akt, phospho-Akt (Ser473), CREB, phospho-CREB (Ser133), caspase-9, and phosphatidylinositide 3-kinase (PI3K) inhibitor (LY294002) were provided by Cell Signaling Technologies (Boston, MA, USA).

\section{Immunofluorescence}

RM-1 cells were cultured on coverslips placed in 6-well plates. For detection of CRFRs expressions, cells were fixed with $100 \%$ methanol for 30 min and washed with PBS for three times. Then, the cells were blocked with $5 \%$ BSA for $30 \mathrm{~min}$ and incubated with goat anti-CRFR1 $(1: 100)$ or $\mathrm{CRFR}_{2}$ antibody $(1: 100)$ overnight at $4{ }^{\circ} \mathrm{C}$. After three washes with PBS, the cells were incubated with a secondary antibody conjugated to $\mathrm{Cy}-3$ for $30 \mathrm{~min}$. During the last $10 \mathrm{~min}$ of the incubation, DAPI was added to stain the nuclei and the slides were visualized under a confocal microscope.

(a) GAPDH
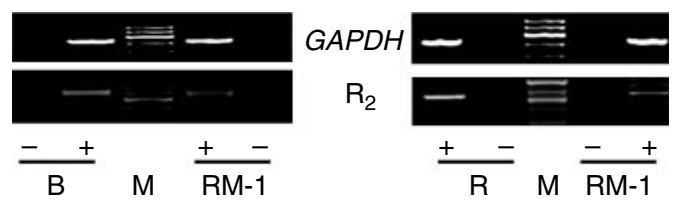

(b)
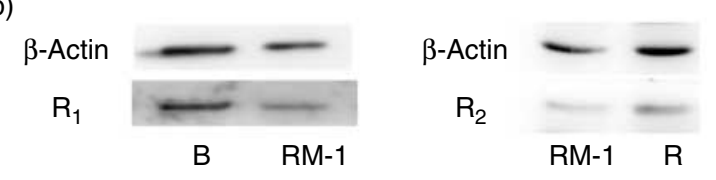

(c)
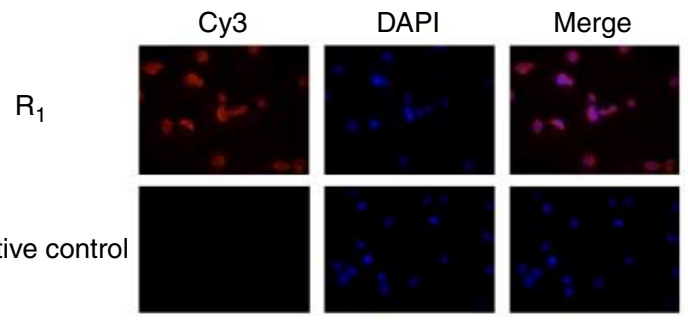

Negative control
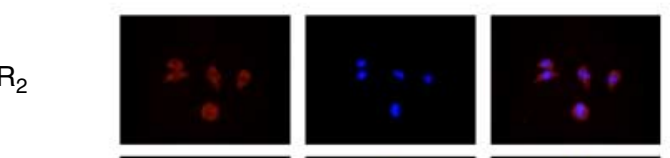

Negative control
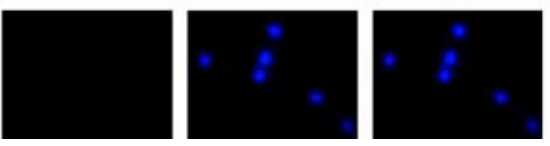

Figure 1 Expressions of CRFR1 and CRFR2 mRNA and protein in RM-1 cells. (a) RT-PCR analysis. M, DNA ladder marker; $\mathrm{B}$, brain; R, renal; -, negative control; +, positive control. (b) Western blot assay. (c) Immunofluorescent staining of CRFR1 and CRFR2 (magnification $400 \times$ ). Treatment of the RM-1 cells without goat anti- $\mathrm{R}_{1} / \mathrm{R}_{2} \mathrm{lg} \mathrm{G}$ showed no red fluorescence (negative control). Experiments were done for more than three times $(n=5)$ and a representative experiment is shown. Full colour version of this figure is available via http://dx.doi.org/10.1530/JME-11-0048. 


\section{Mitochondrial membrane potential assay}

The RM-1 cells pretreated with CRF/Ucn2 and antagonist were incubated with rhodamine-123 (Invitrogen) at a final concentration of $2 \mu \mathrm{g} / \mathrm{ml}$ and then incubated in the dark at $37^{\circ} \mathrm{C}$ for $30 \mathrm{~min}$. The mitochondrial membrane potential (MMP, $\Delta \psi \mathrm{m}$ ) of intact cells was measured by flow cytometry (BD Biosciences, Franklin Lakes, NJ, USA).

\section{Cell viability assay}

The RM-1 and LNCaP cells were seeded in 96-well plates with 6000 cells/well. After incubation with CRF/Ucn2 and antagonists for $48 \mathrm{~h}$, cell viability was determined by $N$ (alpha)-9-fluorenylmethoxycarbonyl- $N$ (epsilon)-4methyltrityl lysine (MTT) assay. The absorbance was measured at $570 \mathrm{~nm}$ in a microtiter reader.

\section{DAPI staining}

The RM-1 cells were cultured in 6-well plates. After treatment with $\mathrm{CRF} / \mathrm{Ucn} 2$ and antagonists, the cells were fixed and washed with PBS and then stained with DAPI. Confocal microscope was used to observe the nuclear morphous of the cells.

\section{Apoptosis assay by flow cytometry}

Annexin V-FITC/PI staining was performed to measure apoptosis by flow cytometry as previously reported (Wang et al. 2008). RM-1 and LNCaP cells were treated in a similar fashion as described above for PI staining. Briefly, cells were washed with PBS and suspended in buffer, added PI at the final concentration of $1 \mu \mathrm{g} / \mathrm{ml}$, and then analyzed with flow cytometry (BD Biosciences).

\section{Semi-quantitative RT-PCR assay}

Total RNAs were extracted from RM-1 cells by TRIzol (Invitrogen). MMLV (Invitrogen) was used as reverse transcriptase, and Taq DNA polymerase (Promega) was added to PCR reaction system. Primer sequences applied in this study are as follows: CRFR1 forward: $5^{\prime}$-ATGTTCGGTGAGGGCTGCTACC- ${ }^{\prime}$ and reverse: $5^{\prime}$-CCTGGAGTCCTTTCAGGGCTTC-3' (Tao et al. 2007); CRFR2 forward: 5'-GGCAAGGAAGCTGGTGATTTG-3' ${ }^{\prime}$ and reverse: 5'-GGCGTGGTGGTCCT-

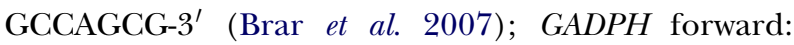
5'-TCCCAGAGCTGAACGGGAAGCTCACTG-3' ${ }^{\prime}$ and reverse: 5'-TGGAGGCCATGTAGGCCATGAGGTCCA-3' (NM_008084.2). PCR products were separated by electrophoresis in $2.0 \%$ agarose gel containing $0.5 \mu \mathrm{g}$ / $\mathrm{ml}$ ethidium bromide. Intensity of objective bands was standardized to that of internal control, GAPDH.

\section{Immunoblotting}

Total protein was collected from cells, and the amount of protein was determined using the Bradford method. The lysates were revolved on SDS-polyacrylamide and then electrically transferred to polyvinylidene fluoride (PVDF) membranes (Millipore, Billerica, MA, USA). Subsequently, the membranes were blocked by $5 \%$ nonfat milk for $2 \mathrm{~h}$ and incubated with primary anti-CRFR antibody (1:200), anti-CRFR 2 antibody (1:200), anti-Bcl2 antibody (1:200), anti-Bax antibody (1:1000), antiCREB antibody (1:1000), anti-phospho-CREB antibody (1:1000), anti-Akt antibody (1:1000), anti-phospho-Akt antibody (1:1000), anti-caspase-9 antibody (1:1000), and anti- $\beta$-actin $(1: 400)$ overnight at $4^{\circ} \mathrm{C}$. After

(a)

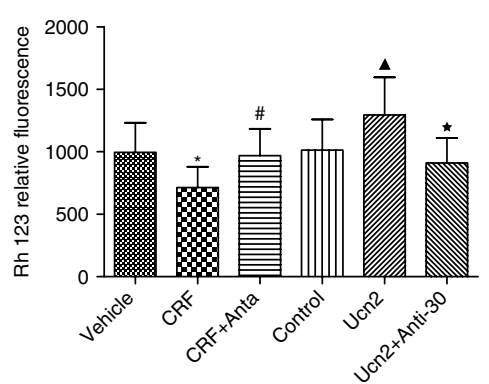

(b)

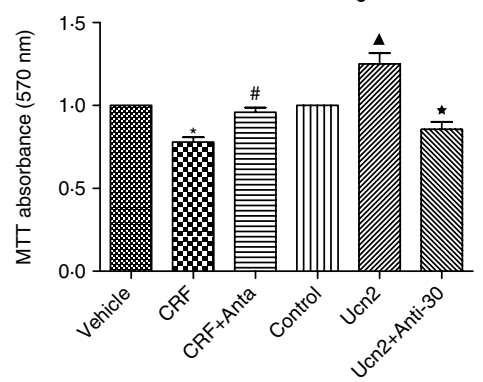

Vehicle

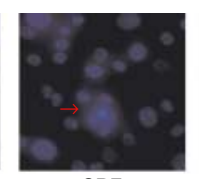

CRF

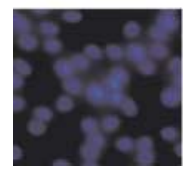

Control

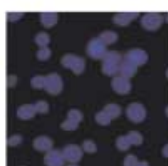

Ucn2

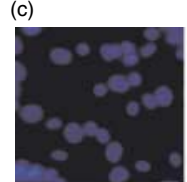

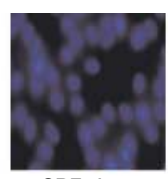

CRF+Anta

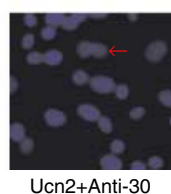

Figure 2 Effect of $\mathrm{CRF} / \mathrm{Ucn} 2$ on mitochondrial membrane potential (MMP), cell viability, and morphological change of nucleus in RM- 1 cells. (a) MMP of RM- 1 cells. (b) Viability of RM-1 cells measured by MTT assay. (c) Fluorescent microscopic analysis of apoptotic cells stained with DAPI (magnification $400 \times$ ). Experiments were done more than three times $(n=4)$ and a representative experiment is shown. Data were expressed as mean \pm S.E.M. of four independent experiments. Significance was determined by Student's $t$-test. ${ }^{*} P<0.05$ versus vehicle group; ${ }^{\#} P<0.05$ versus CRF group; ${ }^{\wedge} P<0.05$ versus control group; $\star P<0.05$ versus Ucn2 group. Full colour version of this figure is available via http://dx.doi.org/10.1530/JME-11-0048. 
incubating with secondary HRP-conjugated IgG for $2 \mathrm{~h}$, protein bands were visualized by enhanced chemiluminescence reagent (Pierce, Rockford, IL, USA) and imaged through X-ray films (Kodak).

\section{Statistical analysis}

The results were expressed as mean \pm s.E.M. Data were analyzed using the SPSS (11.0; SPSS Inc., Chicago, IL, USA) by one-way ANOVA with the Scheffe test or twosided Student's $t$-test. $P<0 \cdot 05$ was considered to be of statistically significance. Each experiment was repeated at least three times.

\section{Results}

\section{Expression of CRFRs in RM-1 cell line}

The expression of CRFR mRNAs from RM-1 cells was detected by RT-PCR. The mouse brain and kidney were set as the positive controls for CRFR1 and CRFR2, respectively, and MMLV was deleted as the negative control. The expression of CRFR proteins from RM-1 cells was detected by western blot and immunofluorescence staining. As shown in Fig. 1, the CRFR mRNAs (a) and proteins (b) were obviously observed in positive controls and RM-1, no signal in negative control was detected. Expressions of CRFRs were monitored in immunofluorescence analysis (Fig. 1c).

\section{CRF reduced MMP levels while Ucn2 enhanced them}

As shown in Fig. 2a, CRF treatment reduced the MMP level of RM-1 cells by $28.35 \%$ and Anta pretreatment invalidated this effect. Conversely, Ucn2 treatment increased MMP level by $27 \cdot 86 \%$, which was abolished by Anti-30 treatment. These results suggest that CRF/ Ucn2 has high potency on MMP, which indicates the effects of CRF/Ucn2 on apoptosis.

\section{Effects of CRF/Ucn2 on cell viability}

As demonstrated in Fig. 2b, treatment with CRF for $48 \mathrm{~h}$ decreased the growth of the RM-1 cells by $22.13 \%$ and Anta treatment invalidated the lower viability. Treatment of the cells with Ucn2 for $48 \mathrm{~h}$ increased the cell viability by $24 \cdot 81 \%$ and Anti-30 abolished the effect.

\section{Morphological changes of nuclei after CRF/Ucn2 treatment}

Morphological analysis of DAPI staining showed that nuclei exhibited chromatin condensation and the formation of apoptotic bodies in RM-1 cells incubated with CRF, and Anta inhibited the nuclei changes
(Fig. 2c). Ucn2 treatment caused little morphological variation in nuclei compared with control (Fig. 2c).

\section{Apoptosis of CRF/Ucn2-treated RM-1 cells}

After Annexin V/PI staining, apoptosis rates of RM-1 cells were detected by flow cytometry (Fig. 3). CRF induced apoptosis (12 vs $3.95 \%$ ) and Anta invalidated this effect $(4.04$ vs $3.95 \%)$ in flow cytometry assay. Ucn2 treatment showed no obvious effects (2.98 vs $4 \cdot 41 \%)$, which may be due to the low apoptotic base of the RM-1 cell line.

\section{CRF induced Bax but repressed $\mathrm{Bcl}-2$ expressions via CRFR1}

In order to gain insight into the mechanisms of CRF on apoptosis, the expression of Bax and Bcl-2 was detected. As depicted in Fig. 4Aa, after treatment with CRF for $24 \mathrm{~h}$ (Mukhopadhaya et al. 2007), expression of Bax was increased in a concentrationdependent manner, with the most significant effect observed at the concentration of $10^{-7} \mathrm{M}$.

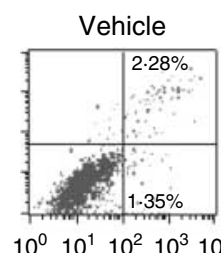

$\begin{array}{rrr}10^{0} & 10^{1} & 10^{2} \\ \mathrm{AV}\end{array}$

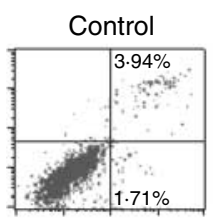

$10^{0} 10^{1} 10^{2}$

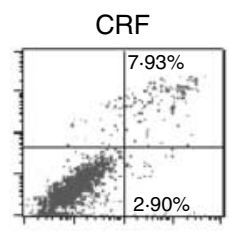

(10) AV

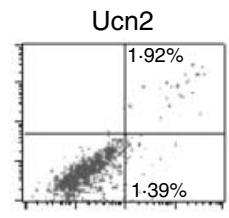

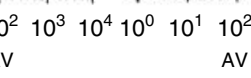

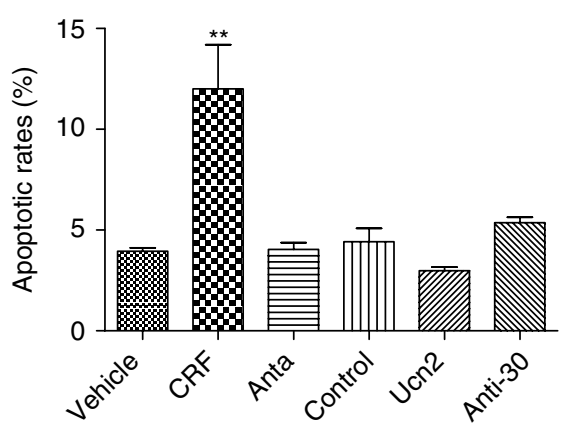

Figure 3 Apoptosis rates of CRF/Ucn2-treated cells by flow cytometry assay. RM-1 cells were treated as above: upper left, necrosis; upper right, late apoptosis; lower left, normal; lower right, early apoptosis. The results are representative of three independent experiments and statistical graph was on the lower side. ${ }^{\star \star} P<0.01$ versus vehicle group. 
Meanwhile, CRF played an inhibitory role in the expression of Bcl-2. These effects were blocked by Anta (Fig. 4Ab).

\section{Ucn2 induced $\mathrm{Bcl}-2$ but repressed Bax expression via CRFR2}

As shown in Fig. 4Ba, Ucn2 concentration-dependently decreased Bax protein expression. The optimal concentration $\left(10^{-7} \mathrm{M}\right)$ was the same as that of CRF. The increased Bcl-2 and decreased Bax expression in Ucn2 treatment was reversed by Anti-30 (Fig. 4Bb and C).

\section{Ucn2 increased Bcl-2 expression through Akt-CREB signal pathway via CRFR2}

Akt, reported to have a wide range of substrates, triggers a group of responses that drive tumor progression,

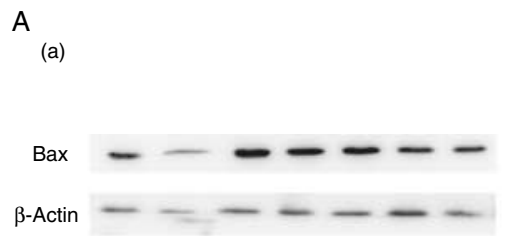

CRF Control $10^{-6} \quad 10^{-7} \quad 10^{-8} \quad 10^{-9} \quad 10^{-10} \quad 10^{-11}$

(b)

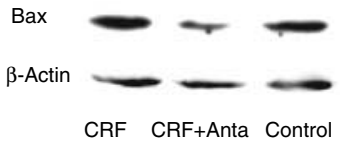

B

$$
\text { Bax }
$$

$\beta$-Actin

Ucn2 Control $10^{-6} \quad 10^{-7} \quad 10^{-8} \quad 10^{-9} \quad 10^{-10} \quad 10^{-11}$

(b)

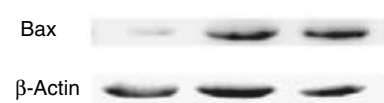

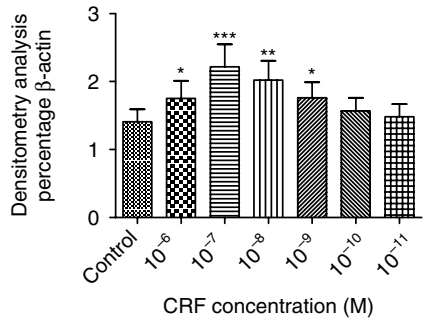

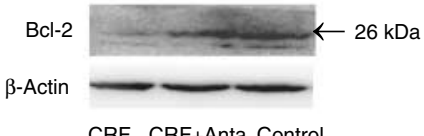

CRF CRF+Anta Control

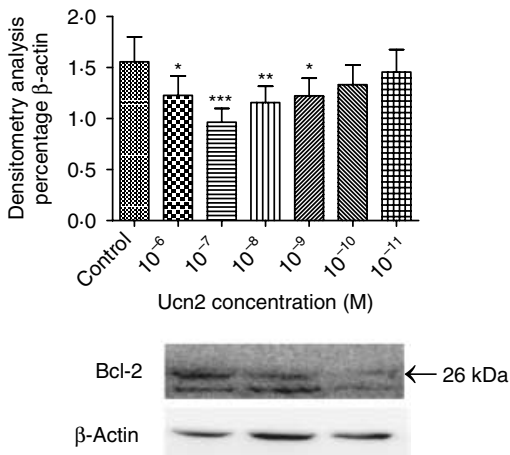

$\mathrm{BCl}-2$

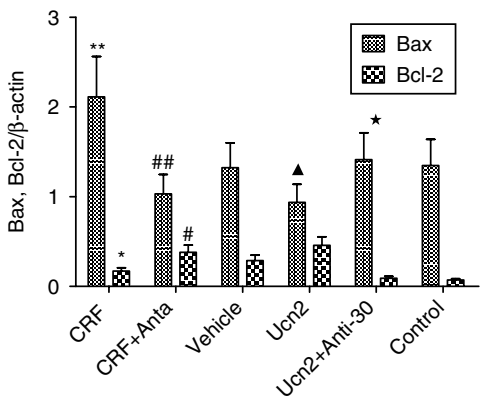

Figure 4 Western blot analysis of CRF and Ucn2 on Bax and Bcl-2 protein expression in $\mathrm{RM}-1$ cells. Cells were treated with $\mathrm{CRF}$ and $U \mathrm{cn} 2$ at concentrations ranging from $10^{-11}$ to $10^{-6} \mathrm{M}$ for $24 \mathrm{~h}$ (Aa and $\mathrm{Ba}$ ). Cells were treated with vehicle/control, CRF $\left(10^{-7} \mathrm{M}\right) / \mathrm{Ucn} 2$ $\left(10^{-7} \mathrm{M}\right)$ alone, or along with antalarmin $\left(10^{-6} \mathrm{M}\right) /$ antisauvagine-30 $\left(10^{-6} \mathrm{M} ; \mathrm{Fig}\right.$. 4Ab and $\mathrm{Bb}$ ). Bar graphs representing densitometry analysis of Fig. $4 \mathrm{Ab}$ and $\mathrm{Bb}(\mathrm{C}) .{ }^{*} P<0.05$ versus vehicle (control) group; ${ }^{\star \star} P<0.01$ versus vehicle (control) group; ${ }^{* \star \star} P<0.001$ versus vehicle (control) group; ${ }^{\prime} P<0.05$ versus CRF group; ${ }^{\# \#} P<0.01$ versus CRF group; $\triangle P<0.05$ versus control group; and ${ }^{\star} P<0.05$ versus Ucn2 group. 
(a)

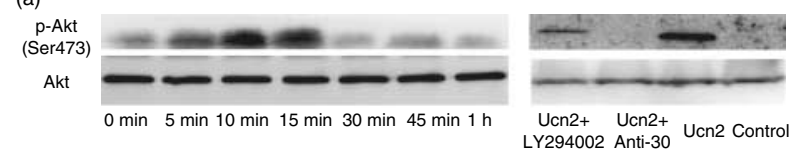

(b)

(b)
p-CREB
(Ser133)

CREB

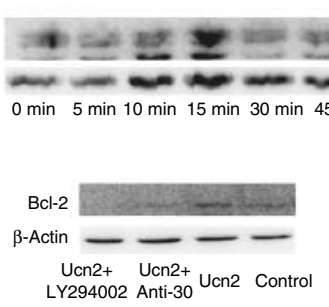

(d)

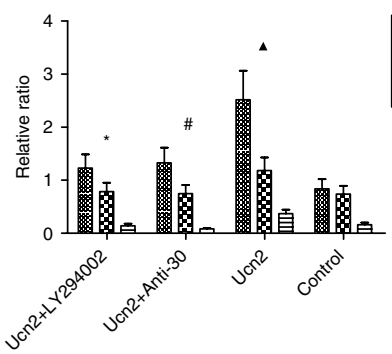

Figure 5 Ucn2 increased Bcl-2 protein expression through Akt and CREB phosphorylation. Time-dependent Akt (a) and CREB (b) phosphorylation exposed to Ucn2 assessed by western blot. Then, Akt inhibitor LY294002 and antisauvagine-30 were used for Akt (a) and CREB (b) phosphorylation and Bcl-2 protein expression (c) examination. Bar graphs presenting densitometry analysis of Fig. 5a, b, and c. ${ }^{\star} P<0.05$ versus Ucn2 group;

${ }^{\#} P<0.05$ versus Ucn 2 group; and $\wedge P<0.05$ versus control group.

from cell growth and proliferation to cell survival and motility (Vivanco \& Sawyers 2002). In this study, we investigated the role of the Akt signal pathway in the effect of CRFR2 on anti-apoptosis protein Bcl-2 expressions. As shown in Fig. 5a, $10^{-7} \mathrm{M} \mathrm{Ucn} 2$ induced time-dependent phosphorylation of Akt peaking at 10 min and pretreatment with PI3K inhibitor blocked this effect. Furthermore, this phosphorylation of Akt could be completely inhibited by Anti-30 (Fig. 5a).

CREB, a positive transcription factor binding to the CRE region of Bcl-2 promoter (Wilson et al. 1996), is mediated in part by Akt-signaling pathway (Belkhiri et al. 2008). To explore whether CREB participates in the upregulation of Bcl-2 expressions, phosphorylation status of CREB was detected by western blot analysis. As demonstrated in Fig. 5b, Ucn2 increased CREB phosphorylation with peak activation observed at the time point of $15 \mathrm{~min}$, Anti-30 significantly, and LY294002 (Akt inhibitor) partly reversed this effect (Fig. 5d). Furthermore, Bcl-2 expressions were decreased in cells treated with LY294002 or Anti-30 plus Ucn2 compared with that treated with Ucn2 alone (Fig. 5c and d).

\section{CRF activated caspase- 9 and hence decreased the total amount of procaspase-9 via CRFR1}

As is well known, Bcl-2 family mediates apoptosis through mitochondria dysfunction and subsequent caspase activation (Hockenbery et al. 1990). Bax oligomerization, forming pores through which cytochrome $c$ is released from the inner mitochondrial membrane into the cytosol, activates caspase-9 (Kuida 2000). As shown in Fig. 6a, $10^{-7} \mathrm{M}$ CRF decreased total amount of pro-caspase-9, which partly cleaved into active caspase-9 (Li et al. 1997) and Anta pretreatment significantly inhibited this cleavage (Fig. 6b).

\section{Effects of CRF and Ucn on LNCaP cell line}

To ascertain the effects of CRF-related peptides on human prostate cancer cells, LNCaP cell line was used to detect cell viability and apoptosis. CRF treatment inhibited the growth of LNCaP by $22.6 \%$ (Fig. 7a) and induced apoptosis by $6 \cdot 21 \%$ (Fig. 7b). Anta reversed the effects by CRF. Ucn 2 treatment increased the viability of LNCaP by $23.7 \%$ (Fig. 7a) and repressed the apoptosis by $6 \cdot 85 \%$ (Fig. 7b). Anti-30 abolished the effects of Ucn2.

\section{Discussion}

In the prostate, cellular growth and differentiation are finely regulated by autocrine and paracrine regulatory factors (Cunha et al. 1987). Ucn, a peptide hormone produced endogenously in human prostate cancer (Arcuri et al. 2002), may be a clinically relevant molecule in the pathogenesis or management of

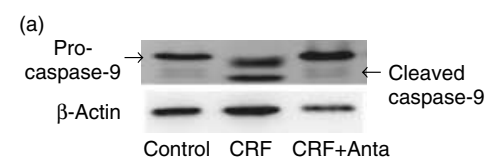

(b)

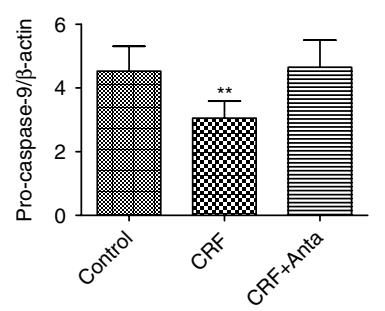

Figure 6 CRF leads to increased cleavage of procaspase- 9 via CRFR1 in RM-1 cells. Immunoblotting for cleavage of caspase-9 using lysates from RM-1 cells treated with vehicle, CRF $\left(10^{-7} \mathrm{M}\right)$, or antalarmin $\left(10^{-6} \mathrm{M}\right)$ for $24 \mathrm{~h}$. Actin was used as the internal control. Data were expressed as mean \pm S.E.M. of three independent experiments. Significance was determined by a Student's $t$-test. ${ }^{\star \star} P<0.01$ versus vehicle group. 
(a)

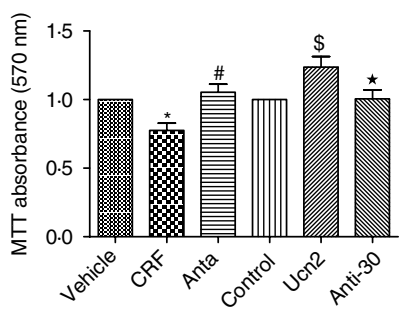

(b)
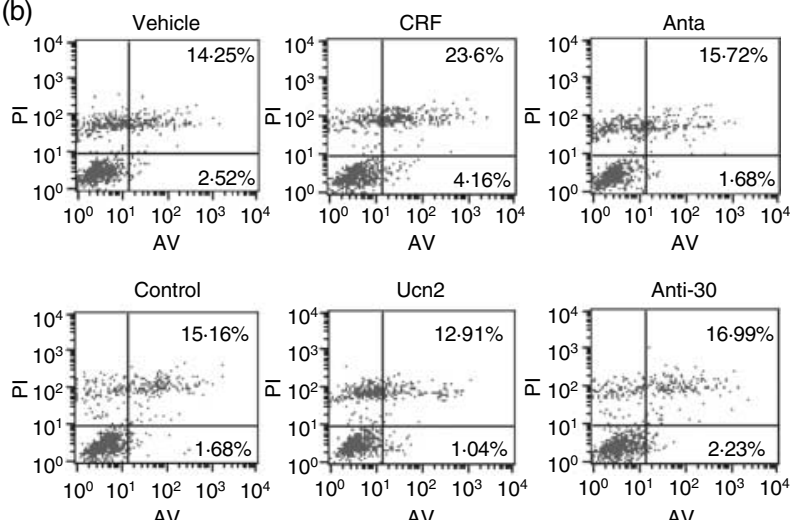

(c)

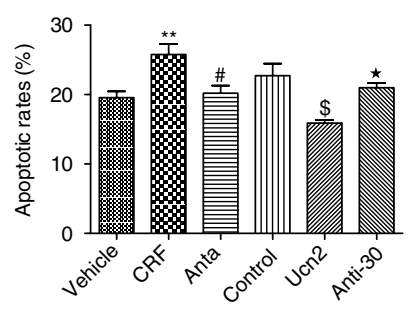

Figure 7 Effect of CRF and Ucn2 on viability and apoptosis of LNCaP. The LNCaP cell line was treated with $10^{-7} \mathrm{M}$ CRF/Ucn2 alone or along with $10^{-6} \mathrm{M}$ antalarmin/antisauvagine-30 for $48 \mathrm{~h}$. Results and statistical graphs of MTT (a) and flow cytometry (b) were represented. ${ }^{\star} P<0.05,{ }^{\star *} P<0.01$ versus vehicle group; ${ }^{\#} P<0.05$ versus CRF group; ${ }^{\$} P<0.01$ versus control group; ${ }^{\star} P<0.05$ versus Ucn2 group.

prostate-related diseases. As we know, the main endogenous CRF peptide is Ucn. However, usage of Ucn does not help to determine the functioning receptor type as Ucn binds with both receptors equally (Vaughan et al. 1995, Fukuda et al. 2005). Therefore, to investigate concrete roles of the two receptors, CRF (R1 agonist) and Ucn2 (R2 agonist) were used instead of Ucn. In this study, the expression of CRFR1 and CRFR2 was first found in murine prostate cell line RM-1. Most interestingly, it was observed that CRF induced apoptosis through reducing the $\mathrm{Bcl} / \mathrm{Bax}$ ratio via CRFR1 while Ucn2 exerted the opposite effect via CRFR2.

It has been proposed that the CRF system plays an important role in various kinds of tumor (Kaprara et al. 2010). Concerning CRF/Ucn effects on apoptosis, some researchers reported that CRF promoted the proliferation of tumor cells (Minas et al. 2007) mainly via
CRFR1, but others argued that CRF was favorable to apoptosis (Graziani et al. 2002) and Ucn/Ucn2 promoted malignant cells growth via CRFR2 (Chatzaki et al. 2006). In this study, we found CRF-promoted and Ucn2-inhibited apoptosis in the RM-1 cell line which supported the hypothesis that endogenous Ucn (equal affinity for CRFR1 and CRFR2) might exert complicated functions in tumor progress, favoring progression of the tumor by CRFR2 and favoring apoptosis and suppression of the tumor by CRFR1. Our previous data showed that Ucn inhibited tumor growth via thwarting angiogenesis in hepatocellular carcinoma (Wang et al. 2008). Tezval et al. (2009) reported that CRFR2 downregulation was associated with prostate cancer development and neovascularization. These results are inconsistent with the present data. Complexity of CRFR1 and CRFR2 effects might contribute to this inconsistency, which needs further clarification.

Bcl-2 family proteins can potentially modulate the cell death pathway through multiple mechanisms such as caspase-independent effects on mitochondria (Hockenbery et al. 1990). Bcl-2, a death suppressor, heterodimerizes with Bax and favors cell survival (Chaudhary et al. 1999). Oligomerization (but not heterodimerization with Bcl-2) of Bax forms pores into the mitochondrial membrane for cytochrome $c$ release, activates caspase cascades, and then leads to membrane potential loss (Hockenbery et al. 1990, Chaudhary et al. 1999) and hence promotes apoptosis. The ratio of Bcl-2 to Bax determines survival or death following apoptotic stimulus (Reed 1994) and can be regarded as a predictive marker for anti-tumor therapy (Kehinde et al. 2008). Thus, upregulation of Bax expression and downregulation of Bcl-2 expression is beneficial to clinical therapy of tumors. This study revealed that CRF/Ucn2 affected apoptosis through mediating the $\mathrm{Bcl}-2 / \mathrm{Bax}$ ratio in a concentrationdependent manner. Both CRF and Ucn2 did not exert the stronger effects on Bax expression levels at $10^{-6}$ $\mathrm{M}$, which might be due to CRF-related peptide autoregulation mechanism (Parham et al. 2004). Furthermore, nuclear morphological variation, change of MMP, and activation of caspase- 9 were discovered. These results suggested that endogenous Ucn could inhibit prostate tumor growth mainly through inducing Bax (a death promoter) expression via CRFR1 and stimulate prostate tumor growth primarily by inducing Bcl-2 (a death suppressor) expression via CRFR2.

Akt activation, involved in Ucn-mediated cell protection (Chanalaris et al. 2005), is a key survival signal in prostate cancer (Walsh et al. 2009) and CREB, an activated transcription factor of $\mathrm{Bcl}-2$, is a survival factor (Wilson et al. 1996). Recent studies reported that increased expression of Bcl-2 was partly mediated by CREB through the convergence of the Akt signaling 
pathway (Belkhiri et al. 2008). In this study, it was found that Ucn2 activated the Akt pathway and subsequently phosphorylated CREB. Furthermore, Anti-30 application could completely abolish the stimulation of Akt and CREB. However, the PI3K inhibitor, LY294002, partially inhibited CREB phosphorylation, which may be attributed to other upstream activators of CREB (Huang et al. 2009). These results illustrated that Ucn2 induced Bcl-2 expression through the Akt/CREB pathway via CRFR2 in RM-1 cells.

CRF and Ucn2 had similar effects on the human LNCaP prostate cancer cell line. CRF repressed the viability and induced the apoptosis of the LNCaP cell line while Ucn2 took an opposite effect. These results revealed that CRF and Ucn2 had opposite effects on cell viability and apoptosis in LNCaP cell line, which was consistent with the results obtained in the RM-1 cell line.

In conclusion, it was demonstrated that CRF and Ucn2 exerted opposite apoptotic effects on prostate cancer cell lines. In the RM-1 cell line, apoptosis promotion was associated with the upregulation of Bax, downregulation of $\mathrm{Bcl}-2$, depolarization of mitochondria, and activation of caspase-9 via CRFR1 while apoptosis repression was accompanied by decreased Bax and increased Bcl-2 expressions via CRFR2. Moreover, the Akt/CREB pathway played important roles in the CRF family-mediated anti-apoptosis. This study first differentiated the active roles of the two CRFRs and the relevant action mechanisms in the RM-1 cell line. Similarly, in the LNCaP human prostate cancer cell line, CRF promoted cell apoptosis while Ucn2 inhibited cell apoptosis. These interesting findings about CRF family peptides add important references for potential therapeutic strategies of prostate cancer.

\section{Declaration of interest}

The authors declare that there is no conflict of interest that could be perceived as prejudicing the impartiality of the research reported.

\section{Funding}

This work was supported by the Natural Science Foundation of China (no. 81072668) and Jiangsu provincial funds (no. BK2010078 and 10KJA350031).

\section{References}

Arcuri F, Cintorino M, Florio P, Floccari F, Pergola L, Romagnoli R, Petraglia F, Tosi P \& Teresa Del Vecchio M 2002 Expression of Urocortin mRNA and peptide in the human prostate and in prostatic adenocarcinoma. Prostate 52 167-172. (doi:10.1002/pros. 10094)

Baley PA, Yoshida K, Qian W, Sehgal I \& Thompson TC 1995

Progression to androgen insensitivity in a novel in vitro mouse model for prostate cancer. Journal of Steroid Biochemistry and Molecular Biology 52 403-413. (doi:10.1016/0960-0760(95) 00001-G)

Belkhiri A, Dar AA, Zaika A, Kelley M \& El-Rifai W 2008 t-Darpp promotes cancer cell survival by up-regulation of Bcl2 through Akt-dependent mechanism. Cancer Research 68 495-503. (doi:10.1158/0008-5472.CAN-07-1580)

Brar BK, Chen A, Perrin MH \& Vale M 2007 Specificity and regulation of extracellularly regulated kinase $1 / 2$ phosphorylation through corticotropin-releasing factor $(\mathrm{CRF})$ receptors 1 and 2 beta by the CRF/Urocortin family of peptides. Endocrinology 145 1718-1729. (doi:10.1210/en.2003-1023)

Cai Y, Lee YF, Li G, Liu S, Bao BY, Huang J, Hsu CL \& Chang C 2008 A new prostate cancer therapeutic approach: combination of androgen ablation with COX-2 inhibitor. International Journal of Cancer 123 195-201. (doi:10.1002/ijc.23481)

Chanalaris A, Lawrence KM \& Townsend PA 2005 Hypertrophic effects of Urocortin homologous peptides are mediated via activation of the Akt pathway. Biochemical and Biophysical Research Communications 328 442-448. (doi:10.1016/j.bbrc.2005.01. 001)

Chatzaki E, Lambropoulou M, Constantinidis TC, Papadopoulos N, Taché Y, Minopoulos G \& Grigoriadis DE 2006 Corticotropinreleasing factor $(\mathrm{CRF})$ receptor type 2 in the human stomach: protective biological role by inhibition of apoptosis. Journal of Cellular Physiology 209 905-911. (doi:10.1002/jcp.20792)

Chaudhary KS, Abel PD \& Lalani EN 1999 Role of the Bcl-2 gene family in prostate cancer progression and its implications for therapeutic intervention. Environmental Health Perspectives 107 49-57. (doi:10.2307/3434471)

Cunha GR, Donjacour AA, Cooke PS, Mee S, Bigsby RM, Higgins SJ \& Sugimura Y 1987 The endocrinology and developmental biology of the prostate. Endocrine Reviews 8 338-362. (doi:10.1210/edrv-8-3338)

Fukuda T, Takahashi K, Suzuki T, Saruta M, Watanabe M, Nakata T \& Sasano H 2005 Urocortin1, Urocortin3/stresscopin, and corticotropin-releasing factor receptors in human adrenal and its disorders. Journal of Clinical Endocrinology and Metabolism 90 4671-4678. (doi:10.1210/jc.2005-0090)

Graziani G, Tentori L, Portarena I, Barbarino M, Tringali G, Pozzoli G \& Navarra P 2002 CRH inhibits cell growth of human endometrial adenocarcinoma cells via CRH-receptor 1-mediated activation of cAMP-PKA pathway. Endocrinology 143 807-813. (doi:10.1210/en. 143.3.807)

Hockenbery D, Nunez G, Milliman C, Schreiber RD \& Korsmeyer SJ $1990 \mathrm{Bcl}-2$ is an inner mitochondrial membrane protein that blocks programmed cell death. Nature 348 334-336. (doi:10.1038/ 348334a0)

Huang M, Kempuraj D, Papadopoulou N, Kourelis T, Donelan J, Manola A \& Theoharides TC 2009 Urocortin induces interleukin-6 release from rat cardiomyocytes through p38 MAP kinase, ERK and NF-kB activation. Journal of Molecular Endocrinology 42 397-405. (doi:10.1677/JME-08-0120)

Jan-Erik D \& Gunnar A 2008 Prostate cancer. Lancet 371 1710-1721. (doi:10.1016/S0140-6736(08)60729-1)

Kaprara A, Pazaitou-Paanayiotou K, Kortsaris A \& Chatzaki E 2010 The corticotropin releasing factor system in cancer: expression and pathophysiological implications. Cellular and Molecular Life Sciences 67 1293-1306. (doi:10.1007/s00018-010-0265-2)

Kehinde EO, Maghrebi MA \& Anim JT 2008 The importance of determining the aggressiveness of prostate cancer using serum and tissue molecular markers. Canadian Journal of Urology 15 3967-3974.

Kuida K 2000 Caspase-9. International Journal of Biochemistry $\mathcal{E}$ Cell Biology 32 121-124. (doi:10.1016/S1357-2725(99)00024-2)

Lewis K, Li C, Perrin MH, Blount A, Kunitake K, Donaldson C, Vaughan J, Reyes TM, Gulyas J, Fischer W et al. 2001 Identification 
of Urocortin III, an additional member of the corticotropinreleasing factor (CRF) family with high affinity for the CRF2 receptor. PNAS 98 7570-7575. (doi:10.1073/pnas.121165198)

Li P, Nijhawan D, Budihardjo I, Srinivasula SM, Ahmad M, Alnemri ES \& Wang X 1997 Cytochrome $c$ and dATP-dependent formation of Apaf-1/caspase-9 complex initiates an apoptotic protease cascade. Cell 91 479-489. (doi:10.1016/S0092-8674(00) 80434-1)

Miceli F, Ranelletti FO, Martinelli E, Petrillo M, Scambia G, Navarra P \& Ferrandina G 2009 Expression and subcellular localization of CRH and its receptors in human endometrial cancer. Molecular and Cellular Endocrinology 305 6-11. (doi:10.1016/j.mce.2009.02. 013)

Minas V, Rolaki A, Kalantaridou SN, Sidiropoulos J, Mitrou S, Petsas G, Jeschke U, Paraskevaidis EA, Fountzilas G, Chrousos GP et al. 2007 Intratumoral CRH modulates immuno-escape of ovarian cancer cells through FasL regulation. British Journal of Cancer 97 637-645. (doi:10.1038/sj.bjc.6603918)

Mukhopadhaya A, Mendecki J, Dong X, Liu L, Kalnicki S, Garg M, Alfieri A \& Guha C 2007 Localized hyperthermia combined with intratumoral dendritic cells induces systemic antitumor immunity. Cancer Research 67 7798-7806. (doi:10.1158/0008-5472.CAN-070203)

Okamoto E, Takagi T, Azuma C, Kimura T, Tokugawa Y, Mitsuda N, Saji F \& Tanizawa O 1990 Expression of the corticotropin-releasing hormone (CRH) gene in human placenta and amniotic membrane. Hormone and Metabolic Research 22 394-397. (doi:10.1055/s-20071004930)

Parham KL, Zervou S, Karteris E, Catalano RD, Old RW \& Hillhouse EW 2004 Promoter analysis of human corticotropin-releasing factor (CRF) type 1 receptor and regulation by CRF and Urocortin. Endocrinology 145 3971-3983. (doi:10.1210/en.2004-0194)

Rajendran RR \& Kao GD 2007 No turning Bax in the combined battle against prostate cancer. Clinical Cancer Research 13 3435-3437. (doi:10.1158/1078-0432.CCR-07-0810)

Reed JC 1994 BcI-2 and the regulation of programmed cell death. Journal of Cell Biology 124 1-6. (doi:10.1083/jcb.124.1.1)

Reyes TM, Lewis K, Perrin MH, Kunitake KS, Vaughan J, Arias CA, Hogenesch JB, Gulyas J, Rivier J, Vale WW et al. 2001 Urocortin II: a member of the corticotropin-releasing factor (CRF) neuropeptide family that is selectively bound by type 2 CRF receptors. PNAS $\mathbf{9 8}$ 2843-2848. (doi:10.1073/pnas.051626398)

Schendel SL, Montal M \& Reed JC 1998 Bcl-2 family proteins as ionchannels. Cell Death and Differentiation 5 372-380. (doi:10.1038/ sj.cdd.4400365)

Suda T, Tomori N, Yajima F, Odagiri E, Demura H \& Shizume K 1986 Characterization of immunoreactive corticotropin and corticotrophin releasing factor in human adrenal and ovarian tumours. Acta Endocrinologica 111 546-552. (doi:10.1530/acta.0. 1110546)

Tao J, Lin M, Sha J, Tan G, Soong TW \& Li S 2007 Separate locations of Urocortin and its receptors in mouse testis: function in male reproduction and the relevant mechanisms. Cellular Physiology and Biochemistry 19 303-312. (doi:10.1159/000102393)

Tezval H, Jurk S, Atschekzei F, Serth J, Kuczyk MA \& Merseburger AS 2009 The involvement of altered corticotropin releasing factor receptor 2 expression in prostate cancer due to alteration of antiangiogenic signaling pathways. Prostate 69 443-448. (doi:10.1002/ pros.20892)

Tsatsanis C, Androulidaki A, Dermitzaki E, Charalampopoulos I, Spiess J, Gravanis A \& Margioris AN 2005 Urocortin 1 and Urocortin 2 induce macrophage apoptosis via CRFR2. FEBS Letters $\mathbf{5 7 9}$ 4259-4264. (doi:10.1016/j.febslet.2005.06.057)

Vaughan J, Donaldson C, Bittencourt J, Perrin MH, Lewis K, Sutton S, Chan R, Turnbull AV, Lovejoy D, Rivier C et al. 1995 Urocortin, a mammalian neuropeptide related to fish urotensin I and to corticotropin-releasing factor. Nature 378 287-292. (doi:10.1038/ $378287 \mathrm{a} 0)$

Vivanco I \& Sawyers CL 2002 The phosphatidylinositol 3-kinase AKT pathway in human cancer. Nature Reviews Cancer 2 489-501. (doi:10. $1038 / \mathrm{nrc839})$

Walsh S, Gill C, O’Neill A, Fitzpatrick JM \& Watson RW 2009 Hypoxia increases normal prostate epithelial cell resistance to receptormediated apoptosis via AKT activation. International Journal of Cancer 124 1871-1878. (doi:10.1002/ijc.24145)

Wang J, Xu Y, Xu Y, Zhu H, Zhang R, Zhang G \& Li S 2008 Urocortin's inhibition of tumor growth and angiogenesis in hepatocellular carcinoma via corticotrophin-releasing factor receptor 2. Cancer Investigation 26 359-368. (doi:10.1080/ $07357900701788106)$

Wilson BE, Mochon E \& Boxer LM 1996 Induction of Bcl-2 expression by phosphorylated CREB proteins during B-cell activation and rescue from apoptosis. Molecular and Cellular Biology $165546-5556$.

Yamamori E, Asai M, Yoshida M, Takano K, Itoi K, Oiso Y \& Iwasaki Y 2004 Calcium/calmodulin kinase IV pathway is involved in the transcriptional regulation of the corticotropin-releasing hormone gene promoter in neuronal cells. Journal of Molecular Endocrinology 33 539-649. (doi:10.1677/jme.1.01415)

Received in final form 17 June 2011

Accepted 14 July 2011

Made available online as an Accepted Preprint 15 July 2011 